\title{
DEMANDA DE EXPORTAÇÃO DE PAINÉIS DE MADEIRA DO BRASIL ${ }^{1}$
}

\author{
Alexandre Anders Brasil ${ }^{2}$ \\ Humberto Angelo ${ }^{3}$ \\ Anadalvo Juazeiro dos Santos ${ }^{4}$ \\ Ricardo Berger ${ }^{4}$ \\ João Carlos Garzel Leodoro da Silva ${ }^{4}$
}

\begin{abstract}
RESUMO
Os painéis de madeira estão consolidando posições de destaque no setor florestal e na economia brasileira, em decorrência do grande crescimento da produção na última década. Os principais motivos desse crescimento foram a instalação de novas unidades produtoras, a busca de novas tecnologias e a modernização do pátio industrial. Conseqüentemente, no ano de 2000, o Brasil alcançou a $10^{\mathrm{a}}$ posição de maior produtor mundial e também a $10^{\mathrm{a}}$ posição de maior exportador mundial. É evidente que no período em análise (1960-2000), os fatores referentes à demanda internacional tiveram um papel importante sobre as exportações brasileiras de painéis de madeira. Os resultados empíricos mostram que as exportações brasileiras de painéis de madeira não são sensíveis ao preço, que as exportações brasileiras de painéis de fibra, painéis de partícula e laminados são complementares às exportações mundiais e que segundo a renda mundial, o compensado brasileiro, indica ser um bem superior, e os demais painéis bens normais.

Palavras-chave: Painéis de madeira, exportação, demanda, Brasil
\end{abstract}

\section{ABSTRACT}

\section{DEMAND FOR BRAZILIAN WOOD-BASED PANELS EXPORTS}

The wood-based panels are consolidating an important position in the Brazilian forest sector and economy, due to its industry growth in the last decade. The main reasons for its growth are the installation of new industrial unities, the search for new technologies, and the industrial modernization. Consequently, in the year 2000, Brazil has reach the $10^{\text {th }}$ position of main world producer and also the $10^{\text {th }}$ position of main world exporter. In the studied period (1960-2000), the international demand had an important role over the Brazilian wood-based panels exports. The empirical results show that the Brazilian wood-based panels are not sensitive to price, that the Brazilian exports of particleboard, fibreboard, and veneers are complementary to the world exports, and that, based in the world revenue, the Brazilian plywood is a superior good and that the other panels are normal goods. Keywords: Wood-based panels, exports, demand, Brazil

\section{INTRODUÇÃO}

Os painéis de madeira estão consolidando posições de destaque no setor florestal brasileiro e na economia brasileira, em decorrência do grande crescimento da produção na última década. Nos anos 90, nenhum outro segmento do setor florestal brasileiro apresentou taxas de crescimento similares aos da indústria de painéis de madeira (Tuoto e Miyake, 2001).

Segundo os relatórios anuais do BNDES (1997, 1999a, 1999b, 2001) os principais

\footnotetext{
${ }^{1}$ Artigo extraído da dissertação de mestrado do primeiro autor

${ }^{2}$ Eng $^{0}$ Florestal, M.Sc. em Economia e Política Florestal, Secretaria de Floresta - SEF do Acre, Gerente de Políticas Públicas Florestais, e-mail: alexbrasil@pop.com.br

${ }^{3}$ Eng $^{0}$ Florestal, M.Sc., Dr., Professor do Departamento de Eng. Florestal da UnB

${ }^{4}$ Eng $^{0}$ Florestal, M.Sc., Dr., Professor do Curso de Eng. Florestal da UFPR
}

Recebido para publicação: 10/12/2002

Aceito para publicação: 04/08/2003 
motivos desse crescimento foram a instalação de novas unidades produtoras, a busca de novas tecnologias de produção e a modernização do pátio industrial, em que se investiu nos últimos cinco anos mais de US\$ 1 bilhão. É inconteste que essa oportunidade foi proporcionada pelo plano Real, em 1992, no qual se adotou o câmbio fixo para a moeda brasileira e pela Política Nacional de incremento das exportações (Revista da Madeira, 2002).

Em conseqüência disso, no período de 1998 a 2000, conforme os dados da FAO (2002), a produção brasileira cresceu $89 \%$, e o Brasil subiu da $15^{\mathrm{a}}$ para a $10^{\mathrm{a}}$ posição de maior produtor mundial no período, com a produção de 3,098, 5,307 e 5,852 milhões de metros cúbicos em 1998, 1999 e 2000, respectivamente. O Brasil também alcançou a posição de $10^{\circ}$ maior exportador mundial com 1,474 e 1,666 milhões de $\mathrm{m}^{3}$ exportados em 1999 e 2000, respectivamente. Na América Latina, o Brasil é o primeiro colocado tanto na produção quanto nas exportações desses produtos.

Tabela 1: Principais continentes e países exportadores de painéis de madeira, 1998-2000

Table 1: Main continents and countries exporters of wood-based panels, 1998-2000

\begin{tabular}{lcc}
\hline \multicolumn{3}{c}{ COMPENSADO } \\
\hline $\begin{array}{c}\text { REGIÃO CONTI- } \\
\text { NENTAL / PAÍS }\end{array}$ & $\begin{array}{c}\text { QUANTUM } \\
\left(\mathrm{em} 1.000 \mathrm{~m}^{3}\right)\end{array}$ & $\begin{array}{c}\text { Participação } \\
\text { Relativa (\%) }\end{array}$ \\
\hline 1 - Asia & 11.278 .125 & 60,6 \\
2 - Europa & 4.073 .912 & 21,9 \\
3 - Am. N/CE & 1.687 .929 & 9,1 \\
4 - Am. do Sul & 1.253 .867 & 6,7 \\
5 - África & 194.503 & 1,0 \\
6 - Oceania & 120.007 & 0,6 \\
1 - Indonésia & 6.643 .867 & 35,7 \\
2 - Malasia & 3.285 .667 & 17,7 \\
3 - Brasil & $\mathbf{1 . 0 0 6 . 3 3 3}$ & $\mathbf{5 , 4}$ \\
4 - China & 979.268 & 5,3 \\
5 - Finlandia & 925.633 & 5,0 \\
6 - Canadá & 892.233 & 4,8 \\
7 - Russia & 874.000 & 4,7 \\
outros & 4.001 .341 & 21,5 \\
& & \\
Mundo & 18.608 .342 & 100 \\
\hline
\end{tabular}

No contexto das exportações, atualmente, um dos principais debates de política econômica refere-se ao desempenho das contas externas do Brasil e em especial, da balança comercial. Assim, dada a importância do tema exportações no atual cenário macroeconômico brasileiro, o presente trabalho tem o objetivo de estimar elasticidades da demanda de exportação de painéis de madeiras do Brasil.

\section{REVISÃO BIBLIOGRÁFICA}

\section{As exportações de painéis de madeira}

As exportações mundiais de painéis de madeira desempenham um importante papel nesse segmento do comércio internacional. No período de 1998 a 2000, as exportações corresponderam a $30,8 \%$ do consumo mundial. As principais regiões continentais e países exportadores de painéis de madeira, para a média do período 1998-2000, podem ser observados na Tabela 01 .

\begin{tabular}{lcc}
\hline \multicolumn{3}{c}{ PAINÉIS DE FIBRA } \\
\hline $\begin{array}{l}\text { REGIÃO CONTI- } \\
\text { NENTAL / PAÍS }\end{array}$ & $\begin{array}{c}\text { QUANTUM } \\
\left(\mathrm{em} 1.000 \mathrm{~m}^{3}\right)\end{array}$ & $\begin{array}{c}\text { Participação } \\
\text { Relativa (\%) }\end{array}$ \\
\hline 1 - Europa & 5.988 .438 & 57,9 \\
2 - Am. N/CE & 1.562 .680 & 15,1 \\
3 - Asia & 1.519 .994 & 14,7 \\
4 - Oceania & 703.667 & 6,8 \\
5 - Am. do Sul & 539.667 & 5,2 \\
6 - África & 34.012 & 0,3 \\
& & 10,7 \\
1 - Alemanha & 1.105 .000 & 10,3 \\
2 - Canadá & 1.066 .967 & 6,6 \\
3 - Malasia & 686.667 & 6,0 \\
4 - França & 624.167 & 5,0 \\
5 - Itália & 515.667 & 4,9 \\
6 - Nova Zelandia & 504.667 & 4,7 \\
7 - Polonia & 483.367 & 51,8 \\
outros & 5.361 .958 & $\mathbf{2 , 2}$ \\
16 - Brasil & $\mathbf{2 3 1 . 6 6 7}$ & 100 \\
Mundo & 10.348 .458 &
\end{tabular}




\begin{tabular}{|c|c|c|}
\hline \multicolumn{3}{|c|}{ PAINÉIS DE PARTÍCULA } \\
\hline $\begin{array}{l}\text { REGIÃO CONTI- } \\
\text { NENTAL / PAÍS }\end{array}$ & 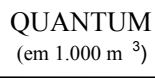 & $\begin{array}{c}\text { Participação } \\
\text { Relativa (\%) }\end{array}$ \\
\hline 1 - Europa & 11.027 .339 & 52,7 \\
\hline $2-\mathrm{Am} . \mathrm{N} / \mathrm{CE}$ & 8.354 .848 & 39,9 \\
\hline 3 - Asia & 1.161 .799 & 5,6 \\
\hline 4 - Am. do Sul & 223.067 & 1,1 \\
\hline 5 - Oceania & 86.000 & 0,4 \\
\hline 6 - África & 19.086 & 0,1 \\
\hline 1 - Canadá & 7.646 .200 & 36,6 \\
\hline 2 - Belgica-Luxemb. & 2.039 .067 & 9,7 \\
\hline 3 - Alemanha & 1.790 .333 & 8,6 \\
\hline 4 - França & 1.324 .800 & 6,3 \\
\hline 5 - Austria & 1.271 .067 & 6,1 \\
\hline $6-$ EUA & 619.667 & 3,0 \\
\hline 7 - Polonia & 515.267 & 2,5 \\
\hline outros & 5.709 .405 & 27,3 \\
\hline 40 - Brasil & 29.667 & 0,1 \\
\hline Mundo & 20.915 .805 & 100 \\
\hline
\end{tabular}

\begin{tabular}{|c|c|c|}
\hline \multicolumn{3}{|c|}{ LAMINADOS } \\
\hline $\begin{array}{l}\text { REGIÃO CONTI- } \\
\text { NENTAL / PAIIS }\end{array}$ & $\begin{array}{l}\text { QUANTUM } \\
\left(\mathrm{em} 1.000 \mathrm{~m}^{3}\right)\end{array}$ & $\begin{array}{l}\text { Participação } \\
\text { Relativa (\%) }\end{array}$ \\
\hline $1-$ Asia & 4.399 .586 & 38,0 \\
\hline $2-\mathrm{Am} \cdot \mathrm{N} / \mathrm{CE}$ & 3.525 .451 & 30,4 \\
\hline 3 - Europa & 1.858 .389 & 16,0 \\
\hline 4 - África & 1.195 .597 & 10,3 \\
\hline $5-$ Am. do Sul & 527.700 & 4,6 \\
\hline 6 - Oceania & 79.562 & 0,7 \\
\hline 1-Malasia & 2.726 .000 & 23,5 \\
\hline 2 - Canadá & 2.277 .452 & 19,7 \\
\hline 3 - EUA & 1.227 .605 & 10,6 \\
\hline 4 - China & 1.143 .436 & 9,9 \\
\hline 5 - Côte d'Ivoire & 422.000 & 3,6 \\
\hline 6 - Cambodia & 359.200 & 3,1 \\
\hline 7 - Alemanha & 357.000 & 3,1 \\
\hline outros & 3.073 .592 & 26,5 \\
\hline 10 - Brasil & 241.000 & 2,1 \\
\hline Mundo & 11.586 .285 & 100 \\
\hline
\end{tabular}

Fonte: FAO (2002). Nota: média 1998-2000; cálculos do autor; Am. N/CE = América do Norte e Central.

No setor agregado de painéis, a Europa é o maior exportador com $40,4 \%$ da oferta $\left(21.709 .152 \mathrm{~m}^{3}\right)$, seguido da Ásia, com $28,7 \%$ $\left(15.426 .446 \mathrm{~m}^{3}\right)$ e da América do Norte/Central, com $23,8 \%\left(12.780 .607 \mathrm{~m}^{3}\right)$. A América do Sul, a Oceania e a África possuem participação marginal, com 4,1\%, $1,8 \%$ e $1,2 \%$, respectivamente. Por país, o Canadá, a Indonésia, a Malásia e a Alemanha são os principais exportadores mundiais de painéis de madeira. Em conjunto, eles participam com $48,3 \%$ das exportações e, separadamente, com $19,3 \%, 13,4 \%, 9,6 \%$ e $6,0 \%$, respectivamente. O Brasil, nesse contexto participa com $2,5 \%$ do total das exportações mundiais de painéis de madeira.

O compensado brasileiro é o principal produto da pauta das exportações brasileiras de

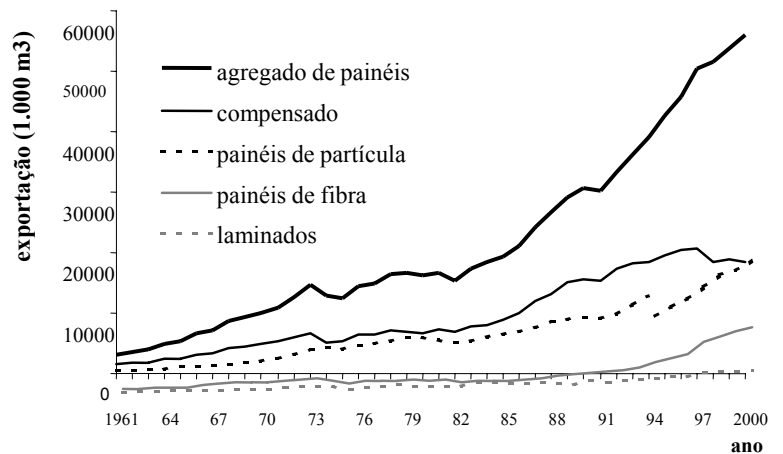

painéis de madeira, sendo o Brasil o terceiro maior exportador mundial desse painel, com participação de apenas $5,4 \%$ da demanda mundial. Para os painéis de fibra o Brasil ocupa a $16^{\mathrm{a}}$ posição de maior exportador mundial, com $2,2 \%$ de participação e para os laminados o Brasil ocupa a $10^{\mathrm{a}}$ posição de maior exportador mundial, com $2,1 \%$ de participação. A participação brasileira nas exportações de painéis de partícula é bastante baixa, ocupando a $40^{\mathrm{a}}$ posição com $0,1 \%$ da demanda.

Ao analisar a evolução das exportações mundiais de painéis de madeira na figura 1 , observa-se que a tendência é crescente para todos os tipos de painéis, embora os painéis de fibra e os painéis de partícula possuam maior crescimento na última década em relação ao compensado e aos laminados.

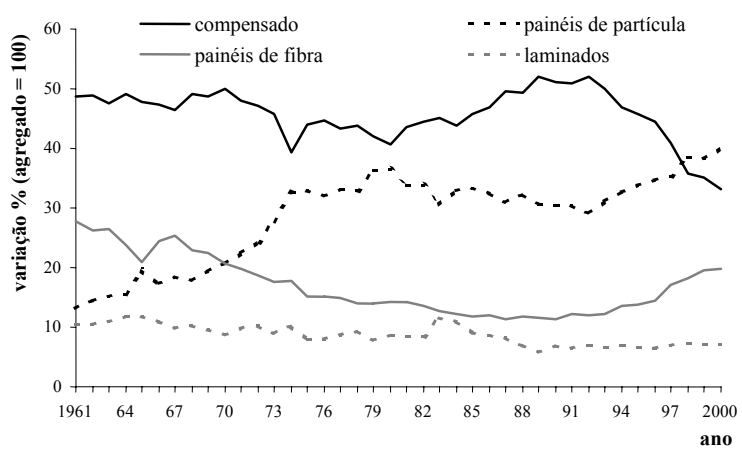

Figura 1: Evolução das exportações mundiais de painéis de madeira, 1961-2000

Figure 1: World wood-based panels exports evolution, 1961-2000

Fonte: FAO (2002), IPA - FMI (2001). Nota: cálculos do autor. 
Os valores da taxa de crescimento das exportações mundiais, para a última década, foram os seguintes: painéis de fibra, 12,8\% a.a.; painéis de partícula, 9,9\% a.a.; laminados, 7,5\% a.a. e compensado, 0,2\% a.a.. Nota-se que na última década, o compensado que sempre houvera sido o principal painel de madeira exportado, a partir de 1997 é ultrapassado pelos painéis de partícula.

Na figura 2 observa-se a evolução real e a participação relativa das exportações brasileiras de painéis de madeiras.
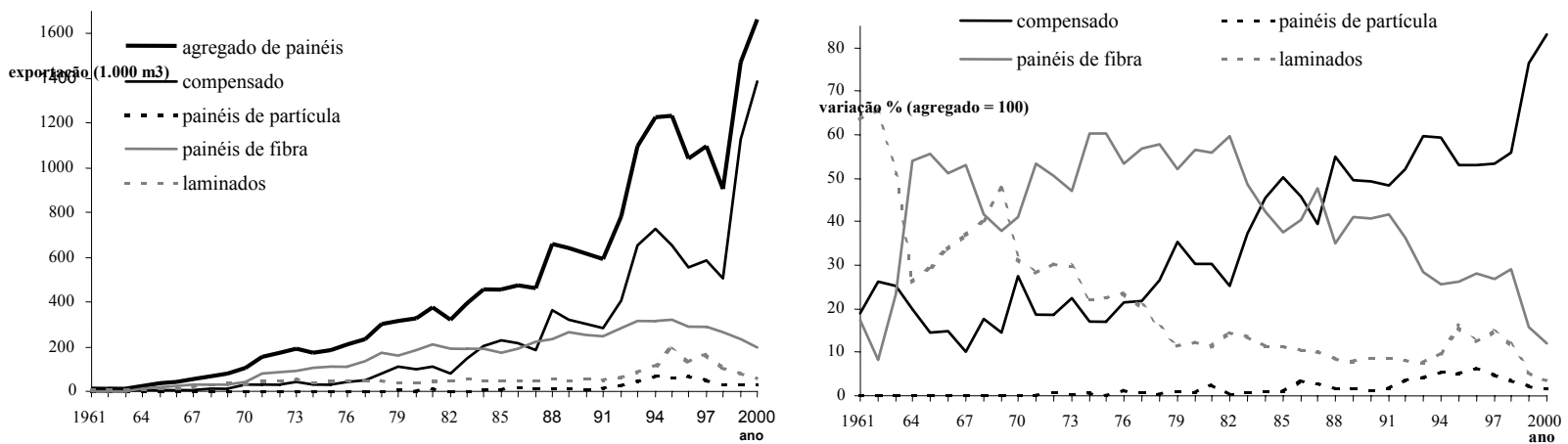

Figura 2: Evolução das exportações brasileiras de painéis de madeira, 1961-2000

Figure 2: Brazilian wood-based panels exports evolution, 1961-2000

Fonte: FAO (2002). Nota: cálculos do autor.

Como se observa nas figuras 1 e 2 , o Brasil segue uma tendência oposta à mundial nas exportações de painéis de madeira. No caso do compensado, enquanto o mundo diminui as exportações, inversamente, o Brasil as aumenta. Já para os painéis de partícula, painéis de fibra e laminados, enquanto o mundo aumenta suas exportações, o Brasil as diminui.

A tendência crescente das exportações brasileiras de painéis de madeira é dada pela

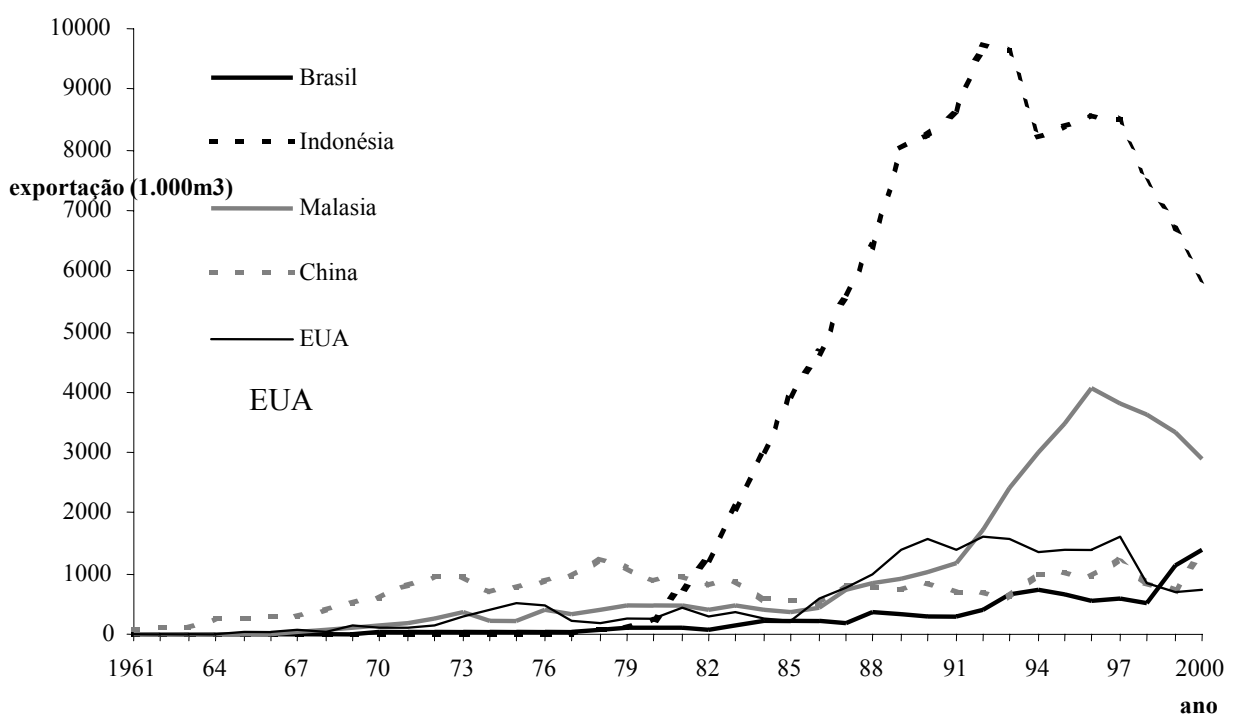

Figura 3: Evolução das exportações dos principais exportadores de compensado, 1961-2000

Figure 3: Main plywood producers exports evolution, 1961-2000

Fonte: FAO (2002) perda de mercado interno do compensado para os painéis de partícula, painéis de fibra e laminados; assim, a alternativa para compensar as perdas com as quedas da demanda interna é encontrada nas exportações (Brasil, 2002).

Nesse contexto, o Brasil, aproveita o mercado deixado pela Indonésia, Malásia e EUA para incrementar suas exportações, conforme pode ser observado na figura 3 . 
Segundo a Revista Referência (2002), devido à crise no mercado do compensado, mais de 30\% das indústrias já fecharam suas portas na Indonésia, maior exportador mundial de compensado.

$\mathrm{O}$ conseqüente aumento de preços no mercado internacional, associado à desvalorização da moeda brasileira, e provavelmente também à queda da renda nacional permitiram ao Brasil o incremento nas exportações. Com isso, as exportações brasileiras de compensado saltou de 33,8\% em 1998 para 57,2\% em 2000 da produção nacional desse produto. No agregado de painéis, o compensado saltou de $56,1 \%$ em 1998 para 83,1\% em 2000 das exportações brasileiras.

Embora o compensado brasileiro tenha encontrado no curto prazo uma solução para a queda na demanda nacional, isso não significa que esta demanda esteja garantida no longo prazo, dada a tendência de queda na demanda mundial por esse produto.

Os principais importadores dos painéis de madeira brasileiros nos anos de 1998 a 2000 são apresentados na tabela 2 .

Tabela 2: Principais importadores dos painéis de madeira brasileiros, 1998-2000

Table 2: Brazilian wood-based panels main importers, 1998-2000

\begin{tabular}{|c|c|c|c|c|}
\hline \multicolumn{5}{|c|}{ COMPENSADO } \\
\hline \multicolumn{5}{|c|}{ Quantum $(1.000 \mathrm{~m}$} \\
\hline & 1998 & 1999 & 2000 & P.R. \\
\hline$\overline{\text { EUA }}$ & 185.652 & 68.000 & 262.277 & $23,3 \%$ \\
\hline Reino-Unido & 115.023 & 109.000 & 232.938 & $20,6 \%$ \\
\hline Alemanha & 53.957 & 68.000 & 155.086 & $12,5 \%$ \\
\hline Bel-Lux & 39.108 & 121.957 & 95.112 & $11,5 \%$ \\
\hline & & & & $67,9 \%$ \\
\hline \multicolumn{5}{|c|}{ PAINÉIS DE PARTÍCULA } \\
\hline \multicolumn{5}{|c|}{ Quantum (1.000 m } \\
\hline & 1998 & 1999 & 2000 & P.R. \\
\hline Alemanha & 32.220 & 8.476 & 320 & $36,6 \%$ \\
\hline Argentina & 3.850 & 1.879 & 15.352 & $18,8 \%$ \\
\hline Itália & 10.991 & 5.341 & 812 & $15,3 \%$ \\
\hline \multirow[t]{2}{*}{ EUA } & 214 & 522 & 4.505 & $4,7 \%$ \\
\hline & & & & $75,3 \%$ \\
\hline
\end{tabular}

\begin{tabular}{|c|c|c|c|c|}
\hline \multicolumn{5}{|c|}{ "PAINÉIS DE FIBRA } \\
\hline \multicolumn{5}{|c|}{ Quantum $(1.000 \mathrm{~m}$} \\
\hline & 1998 & 1999 & 2000 & P.R. \\
\hline EUA & 120.818 & 120.030 & 121.025 & $45,8 \%$ \\
\hline Alemanha & 38.861 & 33.085 & 30.917 & $13,0 \%$ \\
\hline França & 9.117 & 12.480 & 2.015 & $3,0 \%$ \\
\hline Canadá & 11.190 & 3.932 & 4.683 & $2,5 \%$ \\
\hline & & & & $64,4 \%$ \\
\hline \multicolumn{5}{|c|}{ LAMINADOS } \\
\hline \multicolumn{5}{|c|}{ Quantum $(1.000 \mathrm{~m}$} \\
\hline & 1998 & 1999 & 2000 & P.R. \\
\hline$\overline{\text { EUA }}$ & 39.877 & 29.724 & 27.158 & $27,5 \%$ \\
\hline Corea & 62.022 & 26.004 & 10.516 & $28,0 \%$ \\
\hline Israel & 19.342 & 15.067 & 27.019 & $17,5 \%$ \\
\hline \multirow[t]{2}{*}{ Alemanha } & 14.264 & 11.109 & 7.716 & $9,4 \%$ \\
\hline & & & & $82,3 \%$ \\
\hline
\end{tabular}

Fonte: FAO (2002); Nota: P.R. = participação relativa; média 1998-2000; cálculos do autor.

Observa-se que para todos os tipos de painéis, os EUA e a Alemanha sempre estiveram entre os quatro principais importadores para todos os tipos de painéis de madeira brasileiro. Analisando a exportação no agregado de painéis, tabela 3 , observa-se que existe uma grande concentração da compra dos painéis brasileiros pelos EUA, Alemanha, Reino-Unido e Bélgica-Luxemburgo. Em conjunto esses países compraram no período de 1997 a 1999, 62,6\% dos painéis brasileiros exportados. 
Tabela 3: participação total dos principais importadores de painéis brasileiros, 1998-2000

Table 3: Brazilian wood-based panels main importers total participation, 1998-2000

\begin{tabular}{lccc}
\hline PAÍ́S & QUANTUM $\left(1.000 \mathrm{~m}^{3}\right)$ & PARTIC. RELATIVA & PARTIC. ACUMULADA \\
\hline 1. EUA & 979.802 & $28,2 \%$ & $28,2 \%$ \\
2. Alemanha & 482.350 & $13,9 \%$ & $42,1 \%$ \\
3. Reino-Unido & 456.961 & $13,2 \%$ & $55,3 \%$ \\
4. Bel-Lux & 256.177 & $7,4 \%$ & $62,6 \%$ \\
5. Israel & 98.542 & $2,8 \%$ & $65,5 \%$ \\
6. Corea & 33.089 & $1,0 \%$ & $66,4 \%$ \\
7. França & 23.612 & $0,7 \%$ & $67,1 \%$ \\
8. Itália & 21.081 & $0,6 \%$ & $67,7 \%$ \\
9. Canadá & 19.805 & $0,6 \%$ & $68,3 \%$ \\
10. Argentina & 17.144 & $0,5 \%$ & $68,8 \%$ \\
11. Outros & 1.083 .937 & $31,2 \%$ & $100,0 \%$ \\
TOTAL & 3.472 .500 & $100,0 \%$ & \\
\hline
\end{tabular}

Fonte: FAO (2002); Nota: média 1998-2000; cálculos do autor.

\section{MATERIAL E MÉTODOS}

\section{Material}

Os produtos, objeto deste estudo foram o agregado de painéis de madeira, o compensado, os painéis de partícula, os painéis de fibra e os laminados. Os componentes do agregado do produto florestal, painéis de madeira e seus elementos, estão caracterizados abaixo conforme o guia da FAO (2001), Classification and definitions of forest products - Classificação e definições de produtos florestais (figura 4).

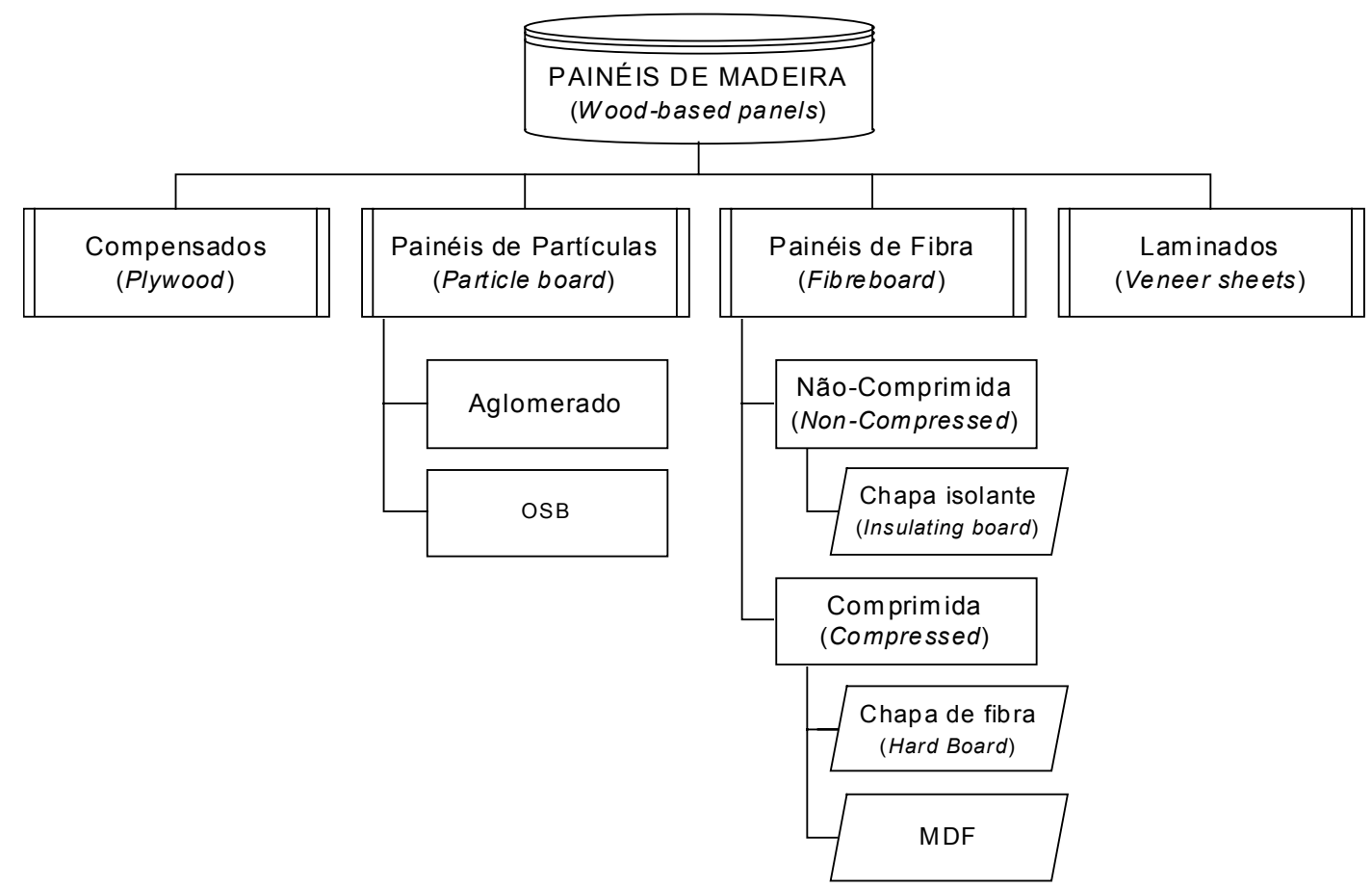

Figura 4: Componentes do agregado do produto florestal, painéis de madeira, FAO

Figure 4: Forestry product, wood-based panels components, FAO

Fonte: UNECE (2001) 
Painéis de Madeira (wood-based panels) - a categoria é um agregado da soma de: laminados, compensados, painéis de partículas e painéis de fibra. Apresentação: $\mathrm{em}^{3}$ de volume sólido. Fonte: FAO (2001).

Compensados (plywood) - painel constituído de um conjunto de laminados colados com a direção $d a$ grã alternada, geralmente em ângulo reto. As lâminas são, usualmente, colocadas simetricamente a partir do centro ou miolo do painel, aos pares em ambos os lados. Inclui: compensado de lâminas (veneer plywood), compensado fabricado pela junção de duas ou mais folhas de madeira, em que a grã das folhas alternadas é cruzada, geralmente em ângulo reto; sarrafeados (core plywood ou blockboard), compensado com o miolo sólido constituído de painéis estreitos, blocos ou faixas de madeira colocadas lado a lado; cellular board, compensado com o miolo de construção celular; composite plywood, compensado com miolo ou certas camadas feitas de materiais outros à madeira sólida ou laminados. Exclui: chapas laminadas em que a grã das lâminas corre para a mesma direção. Apresentação: em $\mathrm{m}^{3}$ de volume sólido. Fonte: FAO (2001).

Painéis de Particula - Aglomerados (particle board) - painel manufaturado a partir de pequenos pedaços de madeira ou de outro material ligno-celulósico (ex.: chips, flakes, splinters, strands, shreds, shives, etc.) unidos pelo uso de aglutinante orgânico e um ou mais dos seguintes agentes: calor, pressão, umidade, catalisador, etc. Inclui: waferboard, OSB e flaxboard. Exclui: lã de madeira e outras partículas unidas com aglutinantes inorgânicos. Apresentação: em $\mathrm{m}^{3}$ de volume sólido. Fonte: FAO (2001).

Painéis de Fibra (fibreboard) - painel manufaturado de fibras de madeira ou de outro material ligno-celulósico em que a primeira colagem se faz com a feltragem (felting) das fibras e seu adesivo inerente (embora outros materiais de colagem e/ou aditivos possam ser adicionados no processo de manufatura). Inclui: painéis de fibra lisos, moldados, chapa isolante (insulating board), chapa de fibra (hardboard) e o MDF. Apresentação: em $\mathrm{m}^{3}$ de volume sólido. Fonte: FAO (2001).

Laminados (veneer sheets) - finas folhas de madeira, de espessura uniforme, laminadas, faqueadas, ou serradas. Inclui: madeiras usadas para a fabricação de compensados, material de construção laminado, móveis, containers laminados, etc. Exclui: laminados utilizados para a produção de compensado dentro do mesmo país. Apresentação: $\mathrm{em}^{3}$ de volume sólido. Fonte: FAO (2001).

\section{A demanda de exportação brasileira}

Do ponto de vista teórico, as possíveis variáveis que condicionam a demanda de exportação de um dado produto de certo país são preço do produto, preço dos substitutos, renda dos países importadores e dos países exportadores, quantidade produzida pelo resto do mundo e outros fatores decorrentes de políticas comerciais: como câmbio, tarifas, subsídios, embargos, estoques, entre outros. A literatura selecionada apresenta uma série de alternativas de estimação da demanda de exportação, contudo a definição das variáveis efetivamente utilizadas nas investigações empíricas, varia de acordo com o país, com o período analisado e com a disponibilidade de dados (Musalem, 1981; Tyler, 1982; Zini Jr., 1988; Cavalcanti e Ribeiro, 1998; Raimundo, 2001; Cruz, 2001).

Para Angelo (1998), a demanda das exportações de produtos madeireiros brasileiros não são oriundas simplesmente do excesso na produção, medida pela diferença entre a oferta e a procura doméstica para a mercadoria. Essa demanda é distinta. Os produtos madeireiros brasileiros não são considerados substitutos perfeitos para $o$ produto doméstico do país importador, ou seja, eles são substitutos imperfeitos. Entre as razões para essas distinções, as principais são a diferença na qualidade do produto $\mathrm{e}$ as diferenças nos procedimentos, leis comerciais e formalidades alfandegárias.

Assim, seguindo o raciocínio de revisões bibliográficas, adotou-se o seguinte modelo para a demanda de painéis de madeira: 


$$
\ln X d_{t}^{i}=\beta_{0}-\beta_{1} \ln P X_{t}^{i}+\beta_{2} \ln P S_{t}^{i}+\beta_{3} \ln Y W_{t}+\varepsilon_{t}
$$

em que

$$
\begin{aligned}
& X d_{t}^{i}=\text { o quantum demandado de exportações brasileiras do painel } i \text { no momento } t \\
& P X_{t}^{i}=\text { o preço FOB das exportações brasileiras do painel } i \text { no momento } t \\
& P S_{t}^{i}=\text { o preço do substituto do painel } i \text { no momento } t \\
& Y W_{t}=\text { a proxy da renda dos países importadores e } \\
& \varepsilon_{t}=\text { termo estocástico. }
\end{aligned}
$$

De acordo com o modelo, na demanda de exportação, $P X$ deve ter sinal negativo, pois espera-se que elevações no nível de preço produzam efeitos negativos nas exportações e $Y W$ deva ter sinal positivo, pois espera-se que o aumento na renda mundial produza efeito positivo nas exportações (Castro e Cavalcanti, 1997).

Não se pode prever o sinal do $P S$, que pode ser positivo ou negativo conforme $\mathrm{o}$ produto brasileiro seja substituto ou complementar no mercado internacional (De Negri, 1998; Fontes e Barbosa, 1991; Medeiros e Teixeira, 1996). A hipótese principal da equação é que $P S$ tenha relação inversa entre $P X$, pois se espera que os painéis de madeira brasileiros substituam a demanda dos principais países exportadores.

\section{Estimação e avaliação dos modelos}

Para a estimação dos modelos, utilizou-se o método dos Mínimos Quadrados Ordinários - MQO, combinado à técnica interativa de Cochrane e Orcutt (1949) para correção da correlação serial entre os resíduos.

Adotaram-se as estatísticas básicas, $\mathrm{F}$ de Snedecor e t de Student, para a verificação das hipóteses de nulidade, o coeficiente de determinação $\mathrm{R}^{2}$ para medir o grau de ajuste do modelo e o teste $d$ de Durbin e Watson (1951) para detectar a correlação serial dos resíduos.

\section{Base e fonte de dados}

Os dados utilizados neste estudo foram séries temporais anuais do período 1961-2000 para as seguintes variáveis.

- Quantidade de painéis de origem doméstica exportada - $(X)$. Medida pelo quantum exportado em $\mathrm{m}^{3}$. Inclui reexportação e exclui remessas em trânsito. Dados da FAO (2002).
- Valor das exportações brasileiras de painéis - $(V)$. Medido pelo preço FOB das exportações brasileiras, em US\$. Dados da FAO (2002).

- Preço FOB das exportações brasileiras de painéis - $(P X)$. Preço medido pelo valor unitário, calculado pelo quociente entre o valor e quantidade exportada, em US\$, deflacionado pelo índice de preços por atacado - IPA (FMI), descrito a seguir. Dados da FAO (2002).

- Quantidade mundial de painéis exportada - $(X W)$. Medida pelo quantum total da exportação mundial, menos o quantum brasileiro, em m². Dados da FAO (2002).

- Valor das exportações mundiais de painéis - $(V M)$. Medido pelo preço FOB das exportações mundiais, menos o valor brasileiro, em US\$. Dados da FAO (2002).

- Preço FOB das exportações mundiais de painéis - $(P S)$. Preço medido pelo valor unitário das exportações mundial de painéis, calculado pelo quociente entre o valor e a quantidade exportada, em US\$, deflacionado pelo índice de preços por atacado - IPA (FMI). Dados da FAO (2002).

- Renda mundial - $(Y W)$. A renda mundial foi medida pela proxy importações mundiais de painéis de madeira, deflacionado pelo índice de preços por atacado - IPA (FMI), descrito a seguir. Dados da FAO (2002).

- Índice de preços por atacado - (IPA). Índice de preços doméstico dos EUA utilizado para deflacionar as séries monetárias nominais em US\$. Dados do FMI (2001).

\section{RESULTADOS E DISCUSSÃO}

O modelo de demanda por exportações brasileiras de painéis de madeira, descrito na 
equação [1], estimado pelo método de Mínimos Quadrados Ordinários - MQO, combinado com a técnica de Cochrane-Orcutt de correção da autocorrelação dos resíduos, ajustou-se satisfatoriamente, exceto para painéis de partícula.

As estimativas das regressões e seus principais resultados são apresentados na tabela 4 a seguir.

Tabela 4 : Equações de demanda de exportação de painéis de madeira brasileiros

Table 4: Brazilian wood-based panels exports demand equations

\begin{tabular}{|c|c|c|c|c|c|}
\hline VARIÁVEIS & $\begin{array}{l}\text { AGREGADO DE } \\
\text { PAINÉIS }^{\mathbf{a}}\end{array}$ & COMPENSADO $^{\mathrm{a}}$ & $\begin{array}{l}\text { PAINÉIS DE } \\
\text { PARTÍCULA }^{\text {a* }}\end{array}$ & $\begin{array}{l}\text { PAINÉIS } \\
\text { DE FIBRA }^{\text {a * }}\end{array}$ & LAMINADOS \\
\hline INTERCEPTO & $\begin{array}{c}0,1297 \\
\left(0,3077^{\mathrm{ns}}\right)\end{array}$ & $\begin{array}{c}0,0038 \\
\left(0,0053^{\mathrm{ns}}\right)\end{array}$ & $\begin{array}{c}0,2625 \\
\left(0,2647^{\mathrm{ns}}\right)\end{array}$ & $\begin{array}{c}2,0835 \\
\left(7,5131^{1}\right)\end{array}$ & $\begin{array}{c}0,8679 \\
\left(1,7355^{3}\right)\end{array}$ \\
\hline PREÇO FOB & $\begin{array}{c}-0,5705 \\
\left(-2,6631^{1}\right)\end{array}$ & $\begin{array}{c}-0,9939 \\
\left(-2,3592^{2}\right)\end{array}$ & $\begin{array}{c}0,5806 \\
\left(2,4558^{2}\right)\end{array}$ & $\begin{array}{c}-0,6017 \\
\left(-2,3138^{2}\right)\end{array}$ & $\begin{array}{c}-0,2908 \\
\left(-2,4124^{2}\right)\end{array}$ \\
\hline $\begin{array}{c}\text { PREÇO DO } \\
\text { SUBSTITUTO }\end{array}$ & $\begin{array}{c}-1,3105 \\
\left(-2,9867^{1}\right)\end{array}$ & $\begin{array}{c}-0,4794 \\
\left(-0,7143^{\text {ns }}\right)\end{array}$ & $\begin{array}{c}0,8537 \\
\left(1,6615^{\mathrm{ns}}\right)\end{array}$ & $\begin{array}{c}-0,5856 \\
\left(-1,8781^{3}\right)\end{array}$ & $\begin{array}{c}-0,6195 \\
\left(-2,0980^{2}\right)\end{array}$ \\
\hline RENDA & $\begin{array}{c}1,4685 \\
\left(5,9310^{1}\right)\end{array}$ & $\begin{array}{c}1,6046 \\
\left(4,3104^{1}\right)\end{array}$ & $\begin{array}{c}0,7630 \\
\left(1,2642^{\mathrm{ns}}\right)\end{array}$ & $\begin{array}{c}0,4329 \\
\left(3,1165^{1}\right)\end{array}$ & $\begin{array}{c}0,8725 \\
\left(3,3881^{1}\right)\end{array}$ \\
\hline $\mathrm{R}^{2}$ & $97,47 \%$ & $92,41 \%$ & $98,40 \%$ & $99,65 \%$ & $96,57 \%$ \\
\hline $\mathrm{F}$ & $338,44^{1}$ & $106,61^{1}$ & $247,16^{1}$ & $1804,65^{1}$ & $225,44^{1}$ \\
\hline DW & $1,6527^{4}$ & $2,2975^{4}$ & $2,3985^{4}$ & $2,2853^{4}$ & $1,8077^{4}$ \\
\hline
\end{tabular}

Valores da estatística $t$ estão entre parênteses; ${ }^{\mathrm{a}}$ correlação serial corrigida pelo método Cochrane-Orcutt; ${ }^{\text {ns }}$ nãosignificativo; ${ }^{1}$ significativo a $99 \%$ de probabilidade; ${ }^{2}$ significativo a $95 \%$ de probabilidade; ${ }^{3}$ significativo a $90 \%$ de probabilidade; ${ }^{4}$ ausente de autocorrelação dos resíduos a 1\% de probabilidade; $* 1972-2000$

Como se observa, as regressões estimadas para demanda, de modo geral, mostraram um bom ajustamento aos dados, exceto para painéis de partícula, em que as variáveis não apresentaram os sinais esperados e/ou não foram significativas.

Para a demanda das exportações brasileiras de painéis de partícula, as variáveis explicativas especificadas não se aplicaram. Acredita-se que esse modelo não tenha apresentado bom ajuste, devido à insignificante participação brasileira de painéis de partícula, na demanda internacional, $0,1 \%$.

Os valores do coeficiente de determinação R2 foram superiores a 92,41\% e o teste DW rejeita a hipótese de autocorrelação dos resíduos a $1 \%$ de probabilidade.

Embora o intercepto do agregado, do compensado e dos painéis de partícula não tenham sido estatisticamente significativos para o agregado e compensado, optou-se por deixá-lo no modelo, visto o intercepto ter sido altamente significativo para os painéis de fibra e laminados. Segundo Gujarati (2000), “a menos que haja uma expectativa a priori bastante forte", aconselha-se utilizar o modelo convencional com intercepto. Mesmo porque, o R2 do modelo sem intercepto é tido como bruto (medido pela soma bruta, não-corrigida pelas médias, de quadrados e produtos cruzados), o qual, embora satisfaça a relação 0 $<\mathrm{R} 2<1$, esse não pode ser comparado diretamente ao valor do R2 convencional.

Outro argumento para o uso do intercepto, assim como para deixar a variável PS de elasticidade-preço-cruzada no modelo do compensado (embora essa também não tenha sido significativa estatisticamente), se baseia na seguinte hipótese do modelo clássico de regressão linear: "o modelo de regressão está corretamente especificado, alternativamente, não há nenhum viés ou erro de especificação no modelo usado na análise empírica". Ou mais genericamente, ao se adotar um determinado modelo de regressão como sendo o modelo "verdadeiro", segundo Gujarati (2000), não se modifica omitindo dele uma ou mais variáveis. Ao não se respeitar esse princípio, provavelmente serão 
subestimadas a variância verdadeira $-\sigma^{2}$, portanto, os erros-padrão estimados do coeficiente de regressão, e assim, obtem-se estimativas viesadas dos parâmetros.

Para o coeficiente PS do compensado, embora esse não tenha sido significativo estatisticamente, segundo Brasil (2002), baseado no modelo de elasticidade-substituição - ES acredita-se que a falta de ajuste para esta variável seja causada pelo fato do Brasil competir elasticamente com as exportações do principal exportador, a Malásia, e competir inelasticamente com as exportações dos EUA, outro principal exportador. Assim, para o somatório das exportações mundiais, dada a variabilidade dos dados, esse não apresentou bom ajuste para PS do compensado.
Para o coeficiente PS do compensado, o resultado não foi estatisticamente significativo. Segundo Brasil (2002), que estimou um modelo de elasticidade de substituição - ES entre os principais países exportadores de compensado, a falta de ajuste da elasticidade-cruzada Brasil/mundo acontece pelo fato das exportações brasileiras de compensado competirem elasticamentente com alguns países e inelasticamente com outros. Assim, para o somatório das exportações mundiais, dada a variabilidade dos dados, esse não apresenta bom ajuste.

A tabela 5 apresenta os resultados das elasticidades dos parâmetros encontrados na equação de demanda de painéis de madeira.

Tabela 5: Elasticidades da demanda de exportação de painéis de madeira brasileiros

Table 5: $\quad$ Brazilian wood-based panels export demand elasticities

\begin{tabular}{cccccc}
\hline VARIÁVEIS & $\begin{array}{l}\text { AGREGADO } \\
\text { PAINÉIS }\end{array}$ & DE COMPENSADO & $\begin{array}{l}\text { PAINÉIS } \\
\text { PARTÍCULA }\end{array}$ & $\begin{array}{l}\text { PAINÉIS } \\
\text { DE FIBRA }\end{array}$ & LAMINADOS \\
\hline PREÇO FOB & $-0,5705$ & $-0,9939$ & $0,5806^{*}$ & $-0,6017$ & $-0,2908$ \\
PREÇO DO & $-1,3105$ & $-0,4794 \mathrm{~ns}$ & $0,8537 \mathrm{~ns}$ & $-0,5856$ & $-0,6195$ \\
SUBSTITUTO & & & & & \\
RENDA & 1,4685 & 1,6046 & $0,7630 \mathrm{~ns}$ & 0,4329 & 0,8725 \\
\hline
\end{tabular}

ns não-significativo, * não obteve o sinal esperado.

A respeito da elasticidade-preço, a do compensado está próxima da unidade, indicando uma demanda unitária em relação ao preço desse produto; assim, o aumento na demanda será proporcional à redução no preço desse bem (ceteris paribus). Segundo Varian (1999), ao se fazer uma analogia do conceito de elasticidade unitária à elasticidade constante, verifica-se que a receita permanece constante para toda variação proporcional de preço e quantidade ao longo da curva de demanda, ou seja, o aumento pela demanda decorrente da queda do preço do produto brasileiro, não trazem um aumento na receita. Assim, dado o equilíbrio de longo prazo, o aumento de $1 \%$ no preço do compensado brasileiro trará a diminuição de $1 \%$ nas exportações e a queda de $1 \%$ no preço trará o aumento de $1 \%$ nas exportações.

Para o agregado, para os painéis de fibra e para os laminados, a elasticidade-preço está abaixo da unidade; isso indica que a demanda de exportação dos painéis de fibra e dos laminados é inelástica em relação às variações de preço, ou seja, para uma variação de $10 \%$ no preço do agregado de painéis, dos painéis de fibra e dos laminados, a demanda cairá respectivamente, $5,7 \%, 6 \%$ e $2,9 \%$. A baixa elasticidade-preço implica numa barreira à expansão das exportações brasileiras, pelo fato de que, mesmo que ocorra um decréscimo nos preços dos referidos painéis, um aumento na demanda seria menos que proporcional a esse decréscimo.

Para o agregado de painéis, Raimundo (2001) também encontrou uma baixa elasticidade-preço, no valor $-0,59$, para o período de 1961-1999, ou seja, um valor bem próximo a $-0,57$, encontrado neste estudo para o período de 1961-2000.

A elasticidade-preço-cruzada demonstra que as exportações brasileiras do agregado de painéis, dos painéis de fibra e dos laminados são complementares às exportações mundiais, ou seja, os painéis brasileiros são consumidos em conjunto com os painéis do resto do mundo e não competem por mercados 
entre si. Assim, constata-se que para o aumento de $10 \%$ na demanda do agregado, dos painéis de fibra e dos laminados do resto do mundo, haverá um aumento de 13,1\%, 5,8\% e $6,1 \%$ na demanda do agregado de painéis, dos painéis de fibra e dos laminados brasileiros, respectivamente. Para o compensado e painéis de partícula a elasticidade-preço-cruzada não foi significativa.

A elasticidade-renda mostra que o único painel de madeira que sofre influência direta no quantum demandado com o aumento de renda é o compensado; assim, o aumento na renda mundial em $1 \%$ aumentou em $1,6 \%$ a demanda por compensados brasileiros. Este é considerado um bem superior pela elasticidade-renda.

Isso já não acontece com os painéis de fibra e com os laminados, cujo aumento na renda internacional faz com que o aumento na demanda por esses painéis seja menos que proporcional a esse aumento. Na magnitude do aumento de $10 \%$ na renda, haverá um aumento de $4,3 \%$ nas exportações de painéis de fibra e de $8,7 \%$ dos laminados. Portanto, os painéis de fibra e os laminados são considerados bens normais.

A elasticidade-renda para o agregado de painéis de madeira assim como para o compensado também se apresenta como um bem superior, cujo coeficiente é de 1,46. Esse resultado revela a grande participação que $o$ compensado tem na pauta do agregado de painéis, uma vez que os painéis de fibra e os laminados tiveram para esse coeficiente valor inferior a 1 .

\section{CONCLUSÕES E RECOMENDAÇÕES}

- É evidente que no período em análise, os fatores referentes à demanda tiveram um papel importante sobre o desempenho das exportações brasileiras de painéis de madeira.

- Os resultados empíricos encontrados mostram que as exportações brasileiras de painéis de madeira não são sensíveis ao preço. Assim, o aumento na demanda oriundo da queda de preço não trará maior receita para o Brasil.

- As exportações brasileiras de painéis de fibra, painéis de partícula e laminados são complementares às exportações mundiais.
- Segundo a renda mundial, o compensado brasileiro, indica ser um bem superior, e os painéis de fibra, os painéis de partícula e os laminados brasileiros são bens normais. De maneira que o compensado brasileiro é sensível ao aumento da renda mundial; ou seja, o aumento da renda mundial proporciona um aumento mais que proporcional na demanda do compensado do que para os demais painéis brasileiros.

- Com base nos resultados deste estudo, infere-se que a expansão da atividade de exportação brasileira deve basear-se nas condições reais de competitividade da indústria nacional, isto é, devem ser canalizados esforços no sentido de aumentar vantagens de produção de escala, preço e promoção do produto brasileiro no mercado internacional.

- Novos esforços de verificação empírica demanda de exportação brasileira de painéis de madeira são justificados. Estudos posteriores devem avaliar os impactos macroeconômicos causados no Brasil após a desvalorização cambial do Real após 1999, avaliar a importância da produção do MDF e OSB no consumo e nas exportações internacionais, bem como avaliar a real inserção do compensado brasileiro no mercado nacional e internacional, com o objetivo de se fazer planejamentos futuros no âmbito industrial e florestal, vista a importância econômica e social do setor para o Brasil.

\section{BIBLIOGRAFIA}

ANGELO, H. As exportações brasileiras de madeira tropical. Curitiba , 1998. 129p. Tese (Doutorado em Ciências Florestais) - Setor de Ciências Agrárias, Universidade Federal do Paraná .

BNDES. Produtos Florestais. Medium Density Fiberboard. Informes Setoriais, 2001.

1999.

Painéis de madeira. BNDES Setorial,

Painéis de Madeira Aglomerada. Informes Setoriais, 1999.

Produtos sólidos de madeira. BNDES Setorial, 1997. 
BRASIL, A. A. As exportações brasileiras de painéis de madeira. Curitiba, 2002. 74p. Dissertação (Mestrado em Ciências Florestais) - Setor de Ciências Agrárias, Universidade Federal do Paraná .

CASTRO, A. S.; CAVALCANTI, M. A. F. H. Estimação de equações de exportação e importação para o Brasil - 1955/95. IPEA, texto para discussão no 469, 1997. 53p.

CAVALCANTI, M. A. F. H.; RIBEIRO, F. J. As exportações brasileiras no período 1977/96: desempenho e determinantes. IPEA, texto para discussão no 545, 1998. 46p.

COCHRANE, D.; ORCUTT, G. H. Application of least squares regressions to relationships containing autocorrelated error terms. Journal of the American Statistical Association, v.44, p.32-61, 1949.

CRUZ, E. S. Análise do comércio mundial de celulose e papel. Lavras, 2001. 145p. Dissertação (Mestrado em Engenharia Florestal) - Universidade Federal de Lavras.

DE NEGRI, J. A. Elasticidade-renda e elasticidade-preço da demanda de automóveis no Brasil. IPEA, texto para discussão no 558, 1998. 21p.

DURBIN, J.; WATSON, G. S. Testing for serial correlation in least-squares regression. Biometrica, v.38, p.159-171, 1951.

FOOD AND AGRICULTURAL ORGANIZATION - FAO. FAO Statistical Database. Disponível em: <http://www.fao.org> Acesso em: fev. 2002. Yearbook of forest products 1999. Rome, 2001. 243p. (FAO Forestry Series, n.34; FAO Statistics Series, n.157)

FUNDO MONETÁRIO INTERNACIONAL FMI. International Financial Statistics, 2001. 1 CD-ROM.

FONTES, R. M. O.; BARBOSA, M. L. Efeitos da integração econômica do Mercosul e da Europa na competitividade das exportações brasileiras de soja. Revista de Economia e Sociologia Rural, v.29, n.4, p.335-351, 1991.

GUJARATI, D. N. Econometria básica. São Paulo, Makron Books, 2000. 846p.
MEDEIROS, V. X.; TEIXEIRA, E. C. Competição no Mercosul e no mercado internacional de carnes. Revista de Economia e Sociologia Rural, v.34, n.1/2, p.49-70, 1996.

MUSALEM, A. R. Política de subsídios e exportações de manufaturados no Brasil. Revista Brasileira de Economia, v.35, n.1, p.17-41, 1981.

RAIMUNDO, Y. M. Análise das exportações Brasileiras de madeira serrada e painéis à base de madeira no período de 1961 a 1999. Piracicaba, 2001. 141 p. Dissertação (Mestrado em Economia Aplicada) - Escola Superior de Agricultura Luiz de Queiroz.

REVISTA DA MADEIRA. Compensado aponta evolução. Curitiba, n.65, p.10-15, 2002.

REVISTA REFERÊNCIA. Mercado externo está aquecido. Curitiba, n.17, p.35-36, 2002.

TUOTO, M.; MIYAKE, N. A indústria de painéis de madeira supera as expectativas. Informativo STCP no 5 - 2001. Curitiba, p.2122, 2001.

TYLER, W. G. O viés antiexportação em políticas comerciais e o desempenho das exportações: alguns aspectos da recente experiência brasileira. Revista Brasileira de Economia, v.36, n.2, p.183-196, 1982.

UNITED NATIONS ECONOMIC COMMISSION FOR EUROPE - UNECE. Forest Products Annual Market Review, 2000-2001. Geneva, v.LIV, n.3, 2001. 185p.

ZINI JR., A. A. Funções de exportação e de importação para o Brasil. Pesquisa e Planejamento Econômico, v.18, n.3, p.615662, 1988. 